\title{
Gene expression profiles during short-term heat stress in the red sea coral Stylophora pistillata
}

\author{
KEREN MAOR-LANDAW ${ }^{1} \dagger$, SARIT KARAKO-LAMPERT ${ }^{1} \dagger$, HIBA WALDMAN BEN-ASHER ${ }^{1}$, \\ STEFANO GOFFREDO ${ }^{2}$, GIUSEPPE FALINI ${ }^{3}$, ZVY DUBINSKY ${ }^{1}$ and OREN LEVY ${ }^{1}$ \\ ${ }^{1}$ The Mina and Everard Goodman Faculty of Life Sciences, Bar Ilan University, Ramat Gan, Israel, ${ }^{2}$ Marine Science Group, \\ Department of Biological, Geological and Environmental Sciences, Section of Biology, Alma Mater Studiorum-University of \\ Bologna, Bologna, Italy, ${ }^{3}$ Dipartimento di Chimica 'G. Ciamician', Alma Mater Studiorum Universita' di Bologna, Bologna, Italy
}

\begin{abstract}
During the past several decades, corals worldwide have been affected by severe bleaching events leading to widespread coral mortality triggered by global warming. The symbiotic Red Sea coral Stylophora pistillata from the Gulf of Eilat is considered an opportunistic ' $r$ ' strategist. It can thrive in relatively unstable environments and is considered a stress-tolerant species. Here, we used a $S$. pistillata custom microarray to examine gene expression patterns and cellular pathways during short-term (13-day) heat stress. The results allowed us to identify a two-step reaction to heat stress, which intensified significantly as the temperature was raised to a $32{ }^{\circ} \mathrm{C}$ threshold, beyond which, coping strategies failed at $34^{\circ} \mathrm{C}$. We identified potential 'early warning genes' and 'severe heat-related genes'. Our findings suggest that during short-term heat stress, S. pistillata may divert cellular energy into mechanisms such as the ER-unfolded protein response (UPR) and ER-associated degradation (ERAD) at the expense of growth and biomineralization processes in an effort to survive and subsequently recover from the stress. We suggest a mechanistic theory for the heat stress responses that may explain the success of some species which can thrive under a wider range of temperatures relative to others.
\end{abstract}

Keywords: coral, gene expression, microarray, stress response

Received 15 September 2013; revised version received 9 February 2014 and accepted 10 February 2014

\section{Introduction}

Coral reefs are among the most spectacular and diverse marine ecosystems on the planet and contain hundreds and thousands of species, many of which remain enigmatic to science (Moberg \& Folke, 1999). Over the past several decades, corals throughout the world have been affected by global warming. Since the onset of the Industrial Revolution and the increased burning of fossil fuels, atmospheric carbon dioxide levels have increased from approximately 280 to 390 ppm, and projections suggest an additional increase of up to 800 ppm by the year 2100 [Intergovernmental Panel on Climate Change (IPCC), 2007;]. Correspondingly, the sea surface temperature (SST) has risen by approximately $0.4{ }^{\circ} \mathrm{C}$ since the 1950 s (Levitus et al., 2009). Frequent episodes of higher SST induce severe coral bleaching events, which typically lead to coral death (Brown, 1997; Hoegh-Guldberg, 2010). Mass coral bleaching events have increased in frequency, intensity and geographical extent over the last three decades, affecting up to $100 \%$ of coral cover across reefs, regions and countries (Hoegh-Guldberg, 2010).

Correspondence: Oren Levy, tel. +97235318030, fax +97237384181, e-mail: oren.levy@biu.ac.il

$\dagger$ These authors contributed equally to this work.
Coral bleaching is associated with the mass expulsion of unicellular photosynthetic dinoflagellate symbionts (Brown, 1997), the suppression of pigment synthesis or both (Weis et al., 2008). Previous studies have established a link between coral bleaching and episodes of exposure to environmental stresses, which are mainly associated with elevated water temperatures (Coles \& Brown, 2003). Bleaching threshold temperatures and mortality vary worldwide and are dependent on geographic location and the mean annual and monthly sea surface temperature conditions (Steen \& Muscatine, 1987).

The development of complementary DNA (cDNA) microarrays for non-model organisms has enabled major advances in coral genomics and bioinformatics research, enabling large scale studies of expression patterns for thousands of genes simultaneously. RNA microarrays have been used to study the transcriptomic response to heat stress in the corals Montastraea faveolata (DeSalvo et al., 2008, 2010), Acropora palmata (DeSalvo et al., 2010), Porites astreoides (Kenkel et al., 2013), the larvae of Montastraea faveolata (Polato et al., 2010), Acropora millepora (Rodriguez-Lanetty et al., 2009) and Acropora palmata (Portune et al., 2010). Other coral studies have utilized this technique to detect responses to darkness (Desalvo et al., 2012), ultraviolet radiation 
(Aranda et al., 2011), and to study coral-algal symbiosis (Voolstra et al., 2009) and phenotypic plasticity (Bay et al., 2009). Several of these stress studies have revealed cellular processes that are active in corals during heat stress, including cytoskeleton reorganization, calcification, $\mathrm{Ca} 2+$ homeostasis, cell death, metabolic modifications and antioxidant and chaperone protein synthesis. However, to date, there is no scientific consensus on the cellular mechanisms underlying bleaching and no distinct pathway has been described (Reaser et al., 2000).

Stylophora pistillata (Esper, 1797) is a scleractinian hermatypic coral commonly occurring in Indo-Pacific coral reefs. Red Sea S. pistillata is an important frame builder in the Gulf of Eilat coral reefs due to its wide abundance that spans from the physically controlled reef flats to environmentally predicted deep reefs. In contrast to the majority of Eilat's scleractinian corals, $S$. pistillata has a wide range of life history characteristics indicating it is an opportunistic ' $r$ ' strategist. It is a pioneer species, colonizing new environments and unpredictable habitats, it develops rapidly, has a large population turnover, reproduces early, has a small body size, short life span, density-independent mortality (often catastrophic) and poor competitive ability (Loya, 1976). Thus, Eilat's Red Sea S. pistillata is known as a stress-tolerant species that thrives in diverse and dynamic environments (Loya, 1976). Consequently, these traits allow for easy maintenance of S. pistillata in aquaria and highlight its potential as a suitable model organism (Weis, 2008), particularly when studying aspects of global change. S. pistillata has been studied for various research topics, including phenotypic plasticity (Shaish et al., 2007), molecular and cellular biology (Weis, 2008), calcification (Gattuso et al., 1999), photosynthesis (Yamashiro, 1995; Gattuso et al., 1999), physiology (Rinkevich \& Loya, 1985) and coral-algae symbiosis (Davy et al., 2012).

Previous studies of Red Sea S. pistillata have shown that this species is relatively resistant to stress conditions (Loya, 1976) and that its thermal threshold is approximately $34{ }^{\circ} \mathrm{C}$ (Shaish et al., 2007). Therefore, in the present research, we focused on the cellular heat stress pathways activated by exposure to a temperature of $34{ }^{\circ} \mathrm{C}$ for 13 days. We present, for the first time, a broad synchronous expression of genes of known cellular functions, namely, the endoplasmic reticulum (ER) unfolded protein response (UPR), ER-associated degradation (ERAD) and ubiquitin-mediated proteolysis. Transcriptome data were analyzed using various bioinformatics tools, and protein interaction networks were constructed based on the up- and down-regulated genes. Additionally, we identified potential 'early warning genes,' i.e. those expressed at temperatures up to $32{ }^{\circ} \mathrm{C}$, as well as a second group of 'severe heatrelated genes' that are expressed at temperatures above $32{ }^{\circ} \mathrm{C}$. These genes can serve as a tool for predicting bleaching events and monitoring subsequent reef recovery worldwide.

\section{Materials and methods}

\section{Coral sampling and experimental design}

During May 2012, a colony of the scleractinian Stylophora pistillata was collected by SCUBA diving at a depth of $10 \mathrm{~m}$ in the Gulf of Eilat (Red Sea). The top of the colony was split into 42 fragments approximately $5 \mathrm{~cm}$ in size. By fragmenting a single colony, we established duplicate 'micro-colonies,' eliminating unwanted sources of biological variability that are associated with corals derived from colonies of different sizes, shapes and thermal/light life histories (Tambutté et al., 1995; Brown et al., 2002).

Following a 1 month acclimation period, the fragments were placed into two aquariums; the control aquarium was maintained at $24{ }^{\circ} \mathrm{C}$, and the experimental aquarium was subjected to an increase of $1{ }^{\circ} \mathrm{C}$ per day from 24 to $34{ }^{\circ} \mathrm{C}$. Three fragments were sampled at the same time of day from both the control and the heat treatment aquariums at time points corresponding to 28,32 and $34{ }^{\circ} \mathrm{C}$, i.e. days 5, 10 and 13 , respectively (sampling was conducted $24 \mathrm{~h}$ after temperature elevation) (see Figure S1). Data S1.

\section{PAM}

An imaging pulse amplitude modulation (IPAM) fluorometer (Heinz Waltz GmbH, Germany) was used to evaluate the photosynthetic efficiency of photosystem II in the algal symbionts. The fluorescence of three S. pistillata fragments was measured following $30 \mathrm{~min}$ of darkness-acclimation at each sampling point $-28,32$ and $34{ }^{\circ} \mathrm{C}$ - corresponding to days $0,5,10$ and 13. The effective quantum yield (Fv/Fm) was calculated for each sample by determining the dark-level fluorescence yield (F0) and the maximum fluorescence yield ( Fm) when all PSII reaction centers were photochemically reduced $[\mathrm{Fv} /$ $\mathrm{Fm}=(\mathrm{Fm}-\mathrm{F} 0) / \mathrm{Fm}]$. The effective quantum yield helped in monitoring the photosynthetic performance during the experiment, which is a putative indicator of thermal stress (Fitt et al., 2001; Ainsworth et al., 2008).

\section{RNA extraction and microarray hybridization}

Total RNA was extracted from each fragment using TRIzol (Invitrogen Life Technologies, Carlsbad, CA, USA) according to the methods presented in (Levy et al., 2007, 2011), and the samples were further purified using an RNA Clean and Concentrator kit (Zymo Research Corp., Irvine, CA, USA). Total RNA was labeled and hybridized against a custom S. pistillata microarray. An Agilent two-color gene expression microarray platform with $8 \times 15 \mathrm{~K}$ probes per slide was used. Oligonucleotide probes (60-mers) were designed based on the 
approximately 12000 genes that are predicted to encode proteins retrieved from a recent de novo assembly of 454sequenced EST libraries of S. pistillata (Karako-Lampert et al., 2014). Labeling and hybridization were conducted using the Agilent Low Input Quick Amp Labeling Kit according to the manufacturer's instructions. The intensity of the emitted fluorescence from a target spot on the array was detected using an Agilent G2565BA microarray scanner. The raw data as well as the processed data of the microarray were deposited under accession number GSE47779 (NCBI GEO, please see; http:// www.ncbi.nlm.nih.gov/geo/query/acc.cgi?token=dxmjvgeye ogkabq\&acc=GSE47779). Stylophora pistillata EST data are also stored at the Cnidarian Database of Centre Scientifique de Monaco: http://data.centrescientifique.mc/CSMdata-home. html (Data S1).

\section{Microarray data analysis}

The data from all arrays were first subjected to background correction and LOESS within-array normalization using Agilent Feature Extraction software (version 9.5.1.1 Agilent Technologies, Santa Clara, CA, USA). The remaining analyses were performed in Partek ${ }^{\circledR}$ Genomics Suite software (version 6.6, Copyright ${ }^{\mathcal{O}} 2012$, Partek Inc., St. Louis, MO, USA). Data from three biological replicates and two to four technical replicates were used to perform a one-way ANOvA. The normalized data were analyzed to identify genes with significantly up- or down-regulated expression [FDR (false discovery rate) $P<0.05$ ] with an arbitrary cutoff of at least a two fold change. We generated networks of highly interconnected proteins using the STRING (Search Tool for the Retrieval of Interacting Genes, Heidelberg, Germany) 9.0 database (Szklarczyk et al., 2011). The clustering of protein interactions with high confidence scores (at least 0.7 ) was examined and subsequently exported to Cytoscape software 2.8 (Smoot et al., 2011) for graphical editing. We focused on main stress- relevant clustering protein groups that consist of multi-interactions connections, as provided by the STRING database. The Gene Ontology (GO) cellular component and biological processes associated with the up- and down-regulated proteins were retrieved from the STRING database and compared between the controls and heat stress treatments. To validate the microarray results, quantitative real-time polymerase chain reaction (qRT-qPCR) assays were performed for four selected genes: two up-regulated and two down-regulated genes. Complementary DNAs were synthesized from the total RNA and the selected genes were amplified using specific qRT-PCR primers. The comparative delta CT method was used to calculate fold changes. Data S1.

\section{Results}

Stylophora. pistillata fragments were subjected to heat stress using a gradual increase in temperature from 24 to $34{ }^{\circ} \mathrm{C}$ over a period of 13 days. Fragments were sampled from both the treatment and control aquariums (the latter was kept at $24{ }^{\circ} \mathrm{C}$ ) when the temperature in the treatment aquarium reached 28,32 and $34{ }^{\circ} \mathrm{C}$; the corresponding samples were referred to as $t 1, t 2$ and $t 3$ and c1, c2 and c3. Using Partek Genomics Suite ${ }^{\mathrm{TM}}$ software, we created a principle component analysis (PCA) that displays the variance of the samples and captures $65.3 \%$ of the total variability for different temperatures and replicates. The PCA revealed that replicate samples were grouped into clusters. All control samples that were sampled throughout the experiment, were grouped together close to $t 1$, whereas the $t 2$ and $t 3$ replicates were grouped separately from the controls as well as from each other (Figure S2).

Each treatment sample was normalized to its control data set, and the resulting RNA expression pattern data were analyzed. Using Partek Genomics Suite ${ }^{\mathrm{TM}}$ software, we constructed a Venn diagram (Figure S3) of all differentially expressed genes (both up- and down-regulated genes with an FDR $P<0.05$ ) to highlight common genes shared among the three treatment time points. The $\mathrm{t} 1\left(28{ }^{\circ} \mathrm{C}\right)$ vs. $\mathrm{c} 1$ and $\mathrm{t} 2\left(32^{\circ} \mathrm{C}\right)$ vs. $\mathrm{c} 2 \mathrm{com}-$ parisons produced lower numbers of differentially expressed genes (963 and 805, respectively) than did the t3 $\left(34{ }^{\circ} \mathrm{C}\right)$ vs. $\mathrm{c} 3$ comparison (one-way ANOvA FDR $P<0.05)$. The transcriptome reaction at the third time point was more intense and included a total of 2229 up(1127 genes) or down- (1102 genes) regulated genes. Moreover, the $34{ }^{\circ} \mathrm{C}$ time point yielded 1481 differentially expressed genes that were neither up- nor downregulated in the previous treatments. A total of 163 genes were either up- or down-regulated at all three sampled temperatures - common genes (Table S1). These results are similar to those acquired from a preliminary experiment that was conducted on short-term heat-stressed $S$. pistillata, when temperatures were elevated from $24{ }^{\circ} \mathrm{C}$ to a maximum of $32{ }^{\circ} \mathrm{C}$. The $28{ }^{\circ} \mathrm{C}$ preliminary treatment did not yield a significant heat stress reaction, and the reaction to the $32{ }^{\circ} \mathrm{C}$ treatment was mild. Two up-regulated and two down-regulated candidate genes were evaluated for the validation of the microarray results using quantitative real-time polymerase chain reaction (qPCR) assays. The calculated fold changes were found to be in the same direction as and consistent with those in the microarray data, thus confirming the microarray results (as described in the supporting information (Figure S4).

The visual color intensity of the heat-stressed coral fragments appeared to fade as the experiment was prolonged, and bleaching was maximized at $34{ }^{\circ} \mathrm{C}$. The photosynthetic efficiency measured using IPAM showed that the Fv/Fm values for the control fragments remained constant throughout the experiment, whereas the heat-stressed fragments showed a significant decrease in the $\mathrm{Fv} / \mathrm{Fm}$ values at $34^{\circ} \mathrm{C}$ (Fig. 1a and b). Results from the Fv/Fm data were subjected to post hoc Tukey's test with significance for $P<0.01$. 
(a)
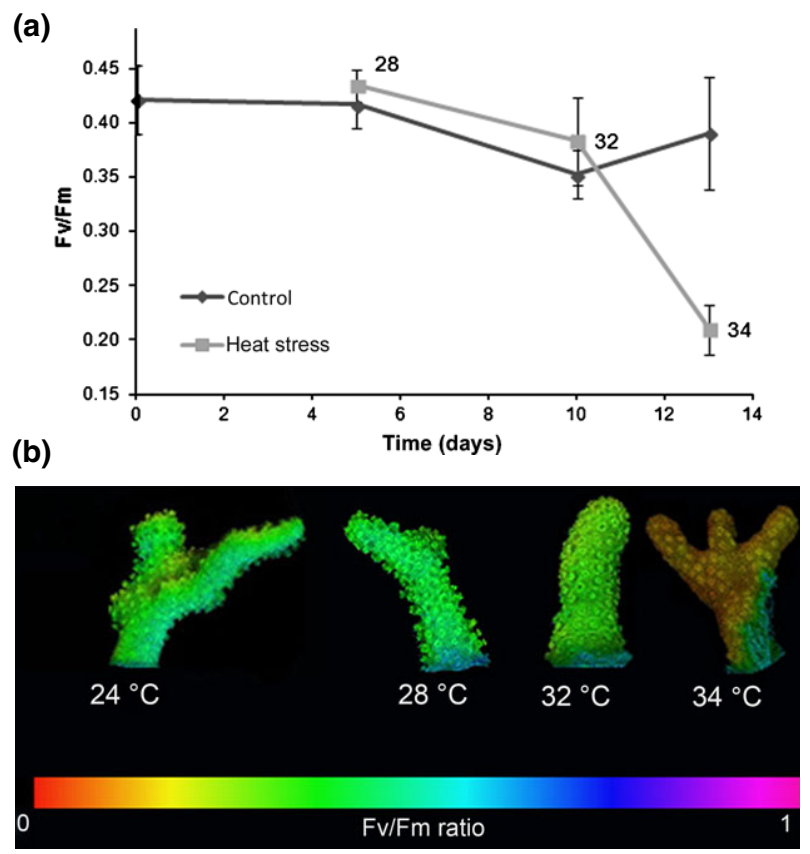

Fig. 1 Photosynthetic efficiency of Stylophora pistillata fragments. (a) Effective quantum yield ( $\mathrm{Fv} / \mathrm{Fm})$ values throughout the experiment for heat-stressed and control fragments. (b) Representative images of effective quantum yield measurements at $24,28,32$ and $34{ }^{\circ} \mathrm{C}$. The relative values of the $\mathrm{Fv} / \mathrm{Fm}$ ratio, ranging from 0 to 1 , are displayed according to the provided color scale.

To examine the cellular processes that occurred in $S$. pistillata cells during severe heat stress, we investigated the interactions among the proteins encoded by genes that were up- or down-regulated at $34{ }^{\circ} \mathrm{C}$. As shown in Fig. 2a, a large group of proteins related to ER stress and protein processing in the ER was up-regulated. This cluster is connected to clusters of up-regulated proteins responsible for cell cycle regulation, cell death and cell death regulation. Proteins involved in ubiquitin-mediated proteolysis also interact with the aforementioned groups of cell death and cell death regulation proteins. Furthermore, cell stress-response proteins, including those involved in sensing and repairing DNA damage, were found to be up-regulated in the $34^{\circ} \mathrm{C}$ heat-stress sample. Nine genes responsible for the regulation of cell-cycle arrest were also up-regulated in this experiment.

A similar analysis performed on cluster groups of down-regulated interacting proteins yielded different results (Fig. 2b). A large core group of proteins that affect the negative regulation of cell death were downregulated in the $34^{\circ} \mathrm{C}$ heat-stress treatment sample. Proteins in the Wnt and Notch signaling pathways as well as four oxidative phosphorylation-related genes were down-regulated in this treatment. Large clusters
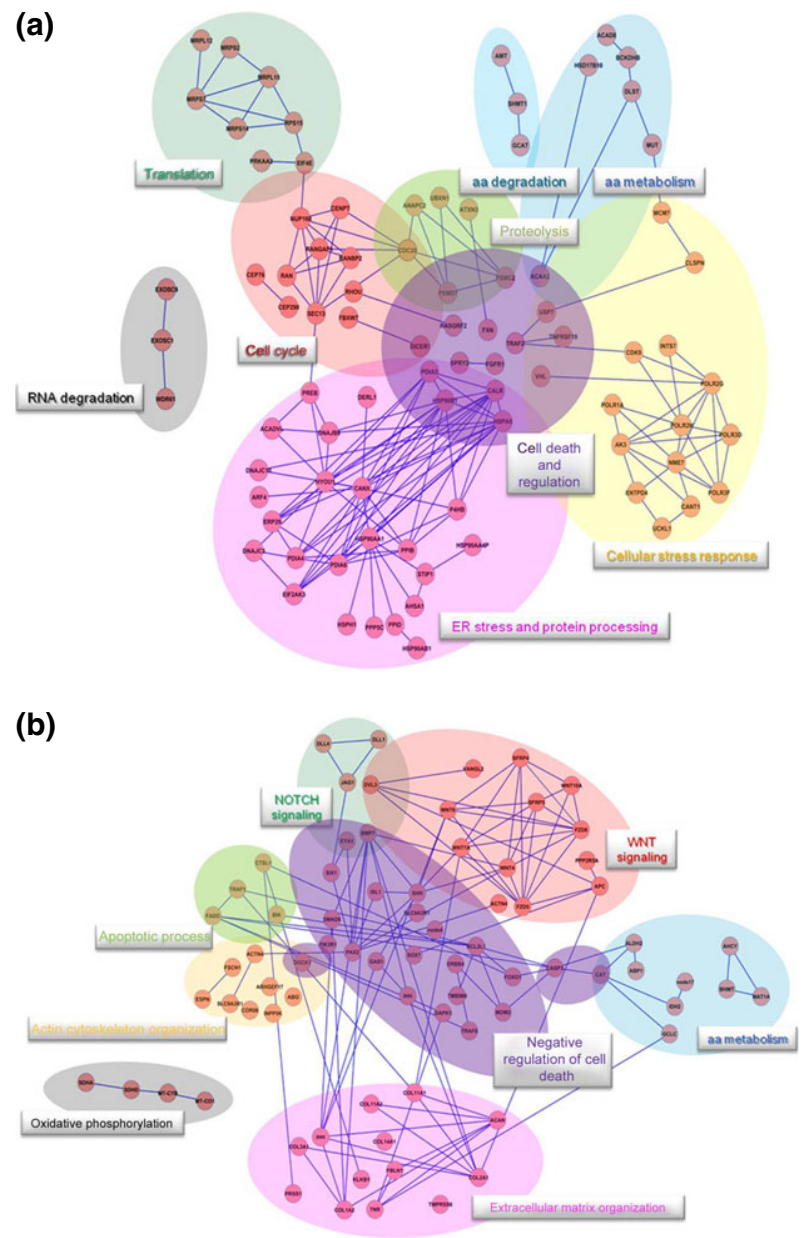

Fig. 2 Protein interaction network of the genes that were upregulated (a) and down-regulated (b) at $34{ }^{\circ} \mathrm{C}$. The $\mathrm{t} 3 \mathrm{vs}$. c 3 data set was uploaded to the Search tool for the retrieval of interacting genes (STRING) database and edited in Cytoscape software. Protein interactions with high confidence scores are categorized based on their Gene Ontology classifications (aa, amino acids; proteolysis, ubiquitin-mediated proteolysis).

of down-regulated proteins with functions in extracellular matrix organization, including several collagen types, were also observed. Actin cytoskeleton organization-related proteins were also among the core group of down-regulated proteins that were associated with the negative regulation of cell death.

Although the strongest cellular reaction to heat stress was observed at the highest temperature treatment, the reaction appears to intensify gradually from 28 to $34{ }^{\circ} \mathrm{C}$, as indicated by the fold change values of the selected up-regulated genes (Figure S5a and b). For example, there was a gradual increase in the up-regulation of genes from the groups involved in ER stress and protein folding in the ER and proteasomal ubiquitin-mediated proteolysis (Figure S5a). Furthermore, genes in relevant down-regulated groups, such as 
extracellular matrix organization, Wnt and Notch signaling and actin cytoskeleton organization, showed gradual changes in the intensity of their fold changes as the experiment progressed and the temperature increased (Figure S5b).

The aforementioned comparison of the protein interaction networks between the $\mathrm{t} 3$ vs. c3 treatments revealed interesting connections of common pathways among the up-regulated genes, which were absent or significantly reduced in quantity and intensity in the $t 2$ vs. $\mathrm{c} 2$ and $\mathrm{t} 1 \mathrm{vs.} \mathrm{c} 1$ treatments. We focused on the largest cluster of up-regulated proteins, which comprised of multiple interconnections between these proteins, ER stress and protein processing in the ER. We identified a total of 62 up-regulated genes in three cellular pathways based on KEGG database annotations: protein processing in the ER, ubiquitin-mediated proteolysis and proteasome function. A graphical representation of these pathways is presented in Fig. 3.

As the temperature increased from 28 to $34{ }^{\circ} \mathrm{C}$ and heat stress was prolonged, the fold changes of the affected genes increased dramatically, and additional genes were added to the same clustering groups that were detected at $32{ }^{\circ} \mathrm{C}$. As shown in Fig. 4, nine genes related to ER stress and protein folding in the ER were up-regulated in the $28^{\circ} \mathrm{C}$ sample. That number increased to 18 in the $32{ }^{\circ} \mathrm{C}$ sample and, following an increase of only $2{ }^{\circ} \mathrm{C}$, an additional 12 genes were added. Similar trends were observed for the proteasomal ubiquitin-mediated proteolysis, extracellular matrix organization and Wnt signaling clusters.

\section{Discussion}

In this study, we explored the ' $\mathrm{r}$ ' strategist S. pistillata coral transcriptome as a case study during short-term heat stress using a microarray technique studying gene expression profiles. A mild heat stress reaction was observed at $28^{\circ} \mathrm{C}$ and intensified significantly at $34^{\circ} \mathrm{C}$. The number of up- and down-regulated genes at 28 and $32{ }^{\circ} \mathrm{C}$ was similar, whereas a sharp increase in the number of differentially expressed genes was observed at $34{ }^{\circ} \mathrm{C}$ (Figure S3). Moreover, variation in the intensity of the heat stress reaction was demonstrated, as the fold change was more pronounced at $34{ }^{\circ} \mathrm{C}$ relative to the lower temperatures (Figure S5a and b). Our preliminary results led us to use higher heat levels in subsequent experiments, as the heat stress reaction to a preliminary $32{ }^{\circ} \mathrm{C}$ treatment was mild. Further analysis justified this enhancement: the preliminary $28{ }^{\circ} \mathrm{C}$ treatment revealed only two up-regulated genes belonging to the $\mathrm{GO}$ response to stress category; at $32{ }^{\circ} \mathrm{C}, 17$ genes from this category were up-regulated, whereas the $34{ }^{\circ} \mathrm{C}$ treatment yielded 41 genes in this category. A similar trend was observed in other GOs, such as proteolysis. In addition, a Venn diagram constructed for the preliminary $32{ }^{\circ} \mathrm{C}$, current $32{ }^{\circ} \mathrm{C}$ treatment and current $34{ }^{\circ} \mathrm{C}$ results showed that the majority of the preliminary $32{ }^{\circ} \mathrm{C}$ up-regulated genes were the same as the current $32{ }^{\circ} \mathrm{C}$ genes, whereas the differentially expressed genes in the $34{ }^{\circ} \mathrm{C}$ treatment were primarily unique (Figure S6).

The cellular heat shock response is characterized by the activation of target genes, such as chaperones and genes related to ubiquitination and proteolysis, defense against oxidative stress, signal transduction, energy generation, vesicular transport and cell wall, cytoskeleton and carbohydrate metabolism (Hahn et al., 2004) (e.g. from a whole yeast genome study). The cellular stress-response genes (Fig. 2) were up-regulated only in response to the $34{ }^{\circ} \mathrm{C}$ temperature treatment. Based on examination of the interconnections between the clusters of the protein processes in the ER, Ubiquitinmediated proteolysis and cell death (Fig. 2), we propose a stress-response pathway (Fig. 3) that highlights protein-encoding genes that were up-regulated following the $34{ }^{\circ} \mathrm{C}$ treatment as well as their known functional roles derived from the principles established in model organisms. Essentially, secretory and membrane proteins synthesized in the ER membrane enter the lumen in an unfolded conformation. While in the ER, peptides assemble, fold and undergo posttranslational modifications. Only properly folded proteins will exit the ER toward the Golgi via a transport vesicle comprising SAR1-GTP, Sec23/24 and Sec13/31 (Barlowe, 1998; Springer et al., 1999), which were increased in the $34{ }^{\circ} \mathrm{C}$ treatment. Unfolded correctly glycoproteins will undergo cycles of interactions with calreticulin and calnexin as a 'quality control' process (Rajagopalan et al., 1994), and ERP57 chaperone can be recruited to form disulfide bonds (Zapun et al., 1998). When luminal chaperones, such as NEF (HYOU1), Hsp40, GRP94 and Bip (Tyedmers et al., 2003)(Haas, 1994), fail to achieve proper protein recognition and folding, peptides tend to accumulate, leading to ER stress, which triggers the unfolded protein response (UPR). Three molecules orchestrate mammalian signaling crosstalk, and one of these, the kinase PERK, was found to be upregulated following the $34{ }^{\circ} \mathrm{C}$ treatment in our experiment. The dissociation of Bip from the PERK luminal domain leads to PERK activation (Walter \& Ron, 2011). PERK inhibits protein translation (Walter \& Ron, 2011), and if the ER stress is not relieved, the UPR will eventually induce apoptosis (Hetz, 2012) and PERK will induce cell cycle arrest (Brewer \& Diehl, 2000). High expression levels of DUB, a gene that was also up-regulated in our experiment, lead to cell cycle arrest (Zhu et al., 1996). As illustrated in Fig. $2 a$ and b, genes 


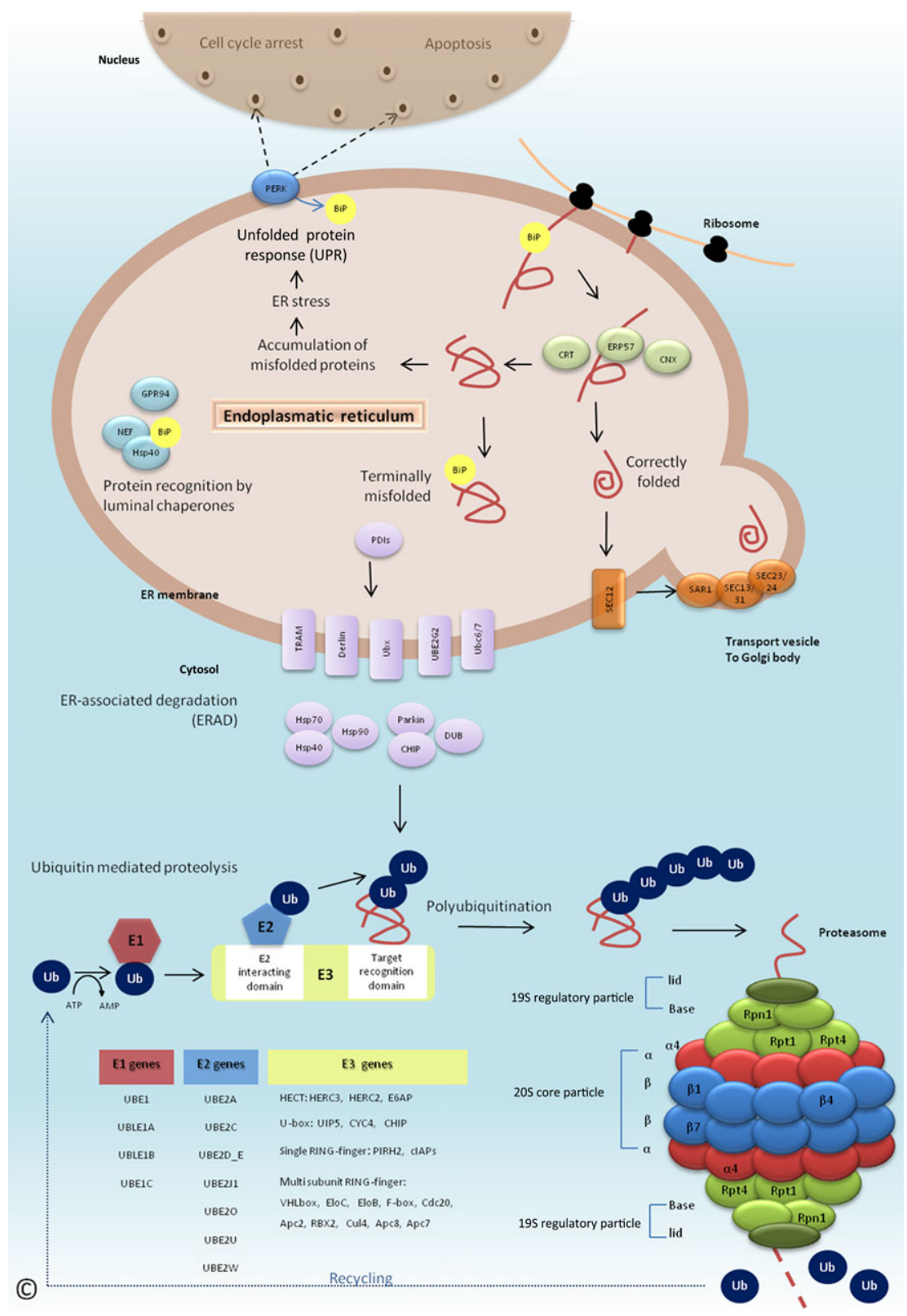

Fig. 3 The endoplasmic reticulum (ER) stress, Unfolded protein response (UPR), ER-associated degradation (ERAD) and ubiquitinmediated proteolysis pathways. All of the genes indicated in this diagram were up-regulated at $34{ }^{\circ} \mathrm{C}$, with the exception of SEC12. The table in the bottom left corner of the figure shows the E1, E2 and E3 enzymes that were found to be up-regulated in our experiment. Based on principles established in model organisms, newly synthesized peptides enter the ER with assistance of the mediator Bip, in an unfolded conformation, where they will assemble, fold and undergo posttranslational modifications. ER lumen chaperones such as NEF (HYOU1), Hsp40, GRP94 and Bip assist with protein folding. CRT, CNX and ERP57 recognize properly folded proteins. Correctly folded proteins will be shuttled via transport vesicles comprising SAR1-GTP, Sec23/24 and Sec13/31 to the Golgi body for final processing and assembly. Misfolded proteins tend to accumulate in the ER lumen and may trigger the unfolded protein response (UPR); the UPR signal is transduced to the nucleus via PERK, resulting in cell cycle arrest. Eventually, if the ER stress is not mitigated, programmed cell death will be initiated. Terminally misfolded proteins undergo ER-associated degradation (ERAD); following binding to Bip and protein reduction and oxidation by PDIs, the protein exits the membrane through one of several adaptor proteins and dislocation components, such as TRAM. Cytosolic E3-protein ligases, such as PARKIN and CHIP, with the assistance of cytosolic heat shock proteins (HSPs), target proteins for degradation via the attachment of ubiquitin molecules. Finally, ERAD substrates are degraded into small peptides by the multi-catalytic $26 \mathrm{~S}$ proteasome. 


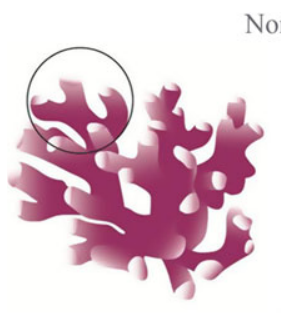

Normal
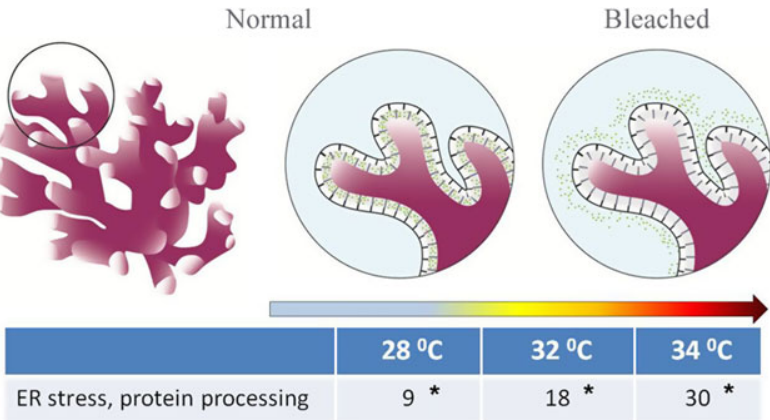

$28{ }^{\circ} \mathrm{C}$

\begin{tabular}{|c|c|c|}
\hline $9^{*}$ & $18^{*}$ & 30 * \\
\hline 2 & 4 & 7 \\
\hline 0 & $8^{*}$ & $11 *$ \\
\hline 0 & 2 & $11 *$ \\
\hline
\end{tabular}

(a)

mediated proteolysis

Extracellular matrix

organization

WNT signaling
Fig. 4 Increasing numbers of genes involved in cellular pathways This figure indicates the number of genes involved in endoplasmic reticulum (ER) stress, protein processing in the ER, proteasomal ubiquitin-mediated proteolysis (up-regulated) and extracellular matrix organization and Wnt signaling (down-regulated) that exhibited differential regulation at each stage of the experiment (from normal healthy colony to bleached). The numbers of significant $(P<0.05)$ genes that are within their Gene Ontology category are indicated by asterisks.

responsible for cell cycle arrest were up-regulated following the $34{ }^{\circ} \mathrm{C}$ heat treatment, and several genes related to programmed cell death were also expressed. Our results suggest that during severe heat stress at $34{ }^{\circ} \mathrm{C}$, S. pistillata cells experience ER stress leading to UPR; if the stress is not mitigated, the cell cycle is arrested and the cell might undergo programmed cell death. Terminally misfolded proteins undergo retrotranslocation to the cytosol and ubiquitin-mediated proteasomal degradation through the ERAD process. Following protein reduction and oxidation by PDIs, the protein exits the membrane through one of several adaptor protein and dislocation components, such as TRAM. Cytosolic E3-protein ligases, such as PARKIN and CHIP, with the assistance of cytosolic heat shock proteins (HSPs), target proteins for degradation via the attachment of ubiquitin molecules (Smith et al., 2011; Kriegenburg et al., 2012). In our experiment, the E3 ligases, as well as the E1 and E2 genes, were up-regulated, as shown in the bottom panel of Fig. 4. Finally, ERAD substrates are degraded into small peptides by the multi-catalytic $26 \mathrm{~S}$ proteasome. The identification of these up-regulated genes involved in ERAD and ubiquitin-mediated proteolysis supports the concept that $S$. pistillata cells utilize these mechanisms to cope with misfolded proteins that aggregate as a result of the heat.

Proteolysis, as reported here, is considered a common end result of heat stress, as is the ubiquitination of proteins designated for degradation. Ubiquitin expression levels have been established as a cellular marker for protein integrity and, hence, cellular heat stress (Downs et al., 2012). Furthermore, increased ubiquitin levels have been documented in heat-stressed cnidarians (Downs et al., 2000, 2002; Yum, 2006). Desalvo et al. (2012) performed microarray analyses showing that genes in the UPR GO category were enriched and a PERK homolog was up-regulated in Acropora palmata under conditions of constant darkness. Kaniewska et al. (Kaniewska et al., 2012) showed that under high $\mathrm{CO}_{2}$ conditions, calnexin gene expression increased in the coral Acropora millepora. However, this study pinpoints on the activities of ER stress, ERAD and UPR processes following heat stress in Anthozoans.

Certain components of the cellular stress response are highly conserved throughout the metazoans with a defined group of proteins indicating a minimal cellular stress proteome (Kültz, 2003). These genes are categorized by their cellular functions, which include redox regulation, DNA damage response, molecular chaperones and energy metabolism. Eleven of the genes from this list were up-regulated in our experiment. Some of these genes were up-regulated in both the 32 and $34{ }^{\circ} \mathrm{C}$ samples, and others were unique to the $34{ }^{\circ} \mathrm{C}$ sample, meaning that they were not up-regulated in the $32{ }^{\circ} \mathrm{C}$ sample or the $28{ }^{\circ} \mathrm{C}$ sample. It is clear that genes associated with redox regulation and chaperones were up-regulated at both 32 and $34{ }^{\circ} \mathrm{C}$, whereas DNA damage-related and energy metabolism genes were largely unique to the $34{ }^{\circ} \mathrm{C}$ sample (see Table 1). Based on these results, we propose a potential time line for the events occurring in S. pistillata cells in response to acute exposure to heat stress: at $32{ }^{\circ} \mathrm{C}$, oxidative damage begins to accumulate in the cells; the thioredoxin expression pattern increases to repair oxidative damage to proteins; and molecular chaperones assist in protein folding. This initial reaction is observed at $32{ }^{\circ} \mathrm{C}$, when the stress is not yet fully realized; thus, these genes can be defined as 'early warning genes.' As the heat is increased to $34{ }^{\circ} \mathrm{C}$, 'severe heat-related genes,' such as those responsible for sensing and repairing DNA damage, are activated. The expression of genes related to energy metabolism increases to satisfy the energetic demands of processes occurring within the cell, such as protein degradation, protein refolding (chaperoning) and DNA repair. Moreover, metabolic enzymes generate reductive elements, such as NADPH and NADH, to address the oxidative damage (Kültz, 2005) that was initiated at lower temperatures $\left(32{ }^{\circ} \mathrm{C}\right)$.

Our transcriptome analysis showed a decrease in actin cytoskeleton- and extracellular matrix organization-related proteins in S. pistillata cells during heat stress. Moreover, we have identified 12 significant 
Table 1 A list of up-regulated genes common to $t 2$ and $t 3$ or unique to $t 3$. The genes are categorized by function. The common lists serve as early warning heat stress genes

\begin{tabular}{|c|c|c|}
\hline & $\begin{array}{l}\mathrm{t} 2 \text { and } \mathrm{t} 3 \text { common } \\
\text { up-regulated genes }\end{array}$ & $\begin{array}{l}\text { t3-unique } \\
\text { up-regulated genes }\end{array}$ \\
\hline \multirow{2}{*}{$\begin{array}{l}\text { redox } \\
\text { regulation }\end{array}$} & Thioredoxin & \\
\hline & Peroxiredoxin & \\
\hline \multirow{3}{*}{$\begin{array}{l}\text { DNA } \\
\text { damage }\end{array}$} & & MutS protein \\
\hline & & $\begin{array}{l}\text { DNA } \\
\text { topoisomerase I }\end{array}$ \\
\hline & & $\begin{array}{l}\text { DNA repair } \\
\text { protein RAD51 }\end{array}$ \\
\hline \multirow{2}{*}{$\begin{array}{l}\text { molecular } \\
\text { chaperones }\end{array}$} & DnaJ & \\
\hline & $\begin{array}{l}\text { Heat shock } \\
70 \mathrm{kDa} \text { protein }\end{array}$ & \\
\hline \multirow{3}{*}{$\begin{array}{l}\text { energy } \\
\text { metabolism }\end{array}$} & $\begin{array}{l}\text { ribosomal RNA } \\
\text { methyltransferase }\end{array}$ & $\begin{array}{l}\text { Plasma membrane } \\
\text { calcium-transporting } \\
\text { ATPase }\end{array}$ \\
\hline & & Enolase \\
\hline & & Phosphoglucomutase \\
\hline
\end{tabular}

(FDR $P<0.05$ ) down-regulated genes from (Drake et al., 2013) the proteomic analysis of the skeletal organic matrix of S. pistillata (Table S2). Similar changes following thermal stress have been reported in previous studies. For example, the down-regulation of actin homologs in the sea anemone (Richier et al., 2008) and changes in actin cytoskeleton organization and extracellular matrix-related proteins in Montastraea faveolata and in Acropora palmata (DeSalvo et al., 2008, 2010) have been observed. In contrast, Barshis et al. (Barshis et al., 2013) reported increases in the expression levels of collagen and extracellular matrix proteins in thermally tolerant populations of Acropora hyacinthus relative to sensitive colonies. It appears that heat stress induced down-regulation of cytoskeleton- and extracellular matrix organization-related proteins impairs the ability to repair the cytoskeleton. However, it has been discussed that heat stress can also directly damage the cytoskeleton's integrity (DeSalvo et al., 2008) or lead to osmotic stress and result in changes in cell volume and fracturing of cytoskeleton elements (Mayfield \& Gates, 2007).

Carbonic anhydrase (CA) was up-regulated at $28{ }^{\circ} \mathrm{C}$ in our experiment, although several transcripts (CA 2, 6, 12, 13 and 14) exhibited a significant decrease in expression at $34{ }^{\circ} \mathrm{C}$. CA catalyzes the hydration of $\mathrm{CO}_{2}$ to $\mathrm{HCO}_{3}{ }^{-}$and is thought to play a significant role in the calcium carbonate assimilation of Scleractinian corals (Tambutté et al., 2006; Bertucci et al., 2011). Several studies have reported the downregulation of coral CAs following stress (Edge et al.,
2005; Desalvo et al., 2012; Kenkel et al., 2013). In addition, a decrease in CA expression was measured in thermally tolerant populations of Acropora hyacinthus following a bleaching event. Accordingly, CA was suggested to promote coral resilience against heat stress (Barshis et al., 2013). Thus, CA down-regulation is consistent with the decreased expression of extracellular matrix organization proteins at $34{ }^{\circ} \mathrm{C}$, as both intracellular (i.e. actin cytoskeleton) and extracellular skeletal elements are damaged when the coral is subjected to thermal stress.

Recent works have highlighted the importance of lectin at the onset of algae-coral symbiosis (WoodCharlson et al., 2006) and showed a decreased transcript concentration before and during coral bleaching (VidalDupiol et al., 2009). Here, we report a significant (FDR $P<0.05)$ down-regulation of lectin, which intensified with higher temperatures, corresponding to bleaching.

Here, we observed a decrease in the expression of 13 Wnt-related genes at $34{ }^{\circ} \mathrm{C}$. Wnt genes are best known as signaling agents with roles in vertebrate and invertebrate developmental processes and cell-cell interactions. Wnt signaling has been shown to promote osteogenesis (Rodda \& McMahon, 2006) and thus may play a role in biomineralization. This outcome is in agreement with previous observations and supports the trend of decreased extracellular matrix assimilation with increasing heat stress. It has also been shown that ER stress can inhibit the Wnt and Notch signaling pathways (Zoltewicz et al., 2009; Aranda et al., 2011), which might provide an additional explanation for the Wnt down-regulation observed in the current study. To date, Lengfeld et al. (Lengfeld et al., 2009) are the only authors who have reported the function and localization of Wnt genes in an adult Cnidaria. These authors demonstrated the expression of seven Wnt genes in the initial stages of bud formation during asexual reproduction in Hydra. If the Wnt cascade has a functional role in asexual budding, it is reasonable to speculate that the Wnt down-regulation that was observed in our experiment may be associated with the inhibition of asexual reproduction processes. Abruptions in gametogenesis and abnormal larval development have been documented following increases in seawater temperature (Szmant \& Gassman, 1990; Bassim et al., 2002). In response to stressors, corals can reallocate their resources accordingly; e.g. energy and resources may be diverted from growth and/or reproduction processes to engage in stress response. Moreover, Obura (2009) suggested a model in which corals that invest in reproduction or growth are more sensitive to bleaching at lower stress levels and are more susceptible to mortality, whereas colonies that devote additional resources to the resistance to stress will bleach only at 
higher levels of stress and will be more resilient to mortality following bleaching events. The subject of our research, the Red Sea Stylophora pistillata, is known for its relative resistance to bleaching and relatively low mortality rates in the Red Sea's Gulf of Aqaba. These characteristics may be consequences of diverting energy toward cellular mechanisms to mitigate stress, such as the ER stress and UPR pathways, with possible negative effects on growth/reproduction and biomineralization processes. Understanding the pathways and cellular mechanisms activated in heat-stressed corals may help improve projections of reef coral survival under the threat of global warming.

\section{Acknowledgements}

We thank Mr. M. Samuelson of the Faculty of Life Sciences, BIU, Israel for his help during this study. This study represents partial fulfillment of the requirements for a $\mathrm{PhD}$ thesis for $\mathrm{K}$. Maor-Landaw at Faculty of Life Sciences Bar-Ilan University, Israel. This research was supported by grant of European Research Council 2009-AdG - 249930 to Z. D. and G. F. We also thank The Interuniversity Institute for Marine Sciences in Eilat (IUI) for the support in this research.

\section{References}

Ainsworth TD, Hoegh-Guldberg O, Heron SF, Skirving WJ, Leggat W (2008) Early cellular changes are indicators of pre-bleaching thermal stress in the coral host. Journal of Experimental Marine Biology and Ecology, 364, 63-71.

Aranda M, Banaszak AT, Bayer T, Luyten JR, Medina M, Voolstra CR (2011) Differential sensitivity of coral larvae to natural levels of ultraviolet radiation during the onset of larval competence. Molecular ecology, 20, 2955-2972.

Barlowe C (1998) COPII and selective export from the endoplasmic reticulum. Biochimica et Biophysica Acta, 1404, 67-76.

Barshis DJ, Ladner JT, Oliver T a, Seneca FO, Traylor-Knowles N, Palumbi SR (2013) Genomic basis for coral resilience to climate change. Proceedings of the National Academy of Sciences of the United States of America, 110, 1387-1392.

Bassim M, Sammarco W, Snell L (2002) Effects of temperature on success of (self and non-self) fertilization and embryogenesis in Diploria strigosa (Cnidaria, Scleractinia). Marine Biology, 140, 479-488.

Bay LK, Ulstrup KE, Nielsen HB et al. (2009) Microarray analysis reveals transcriptional plasticity in the reef building coral Acropora millepora. Molecular ecology, 18, 3062-3075.

Bertucci A, Tambutté S, Supuran CT, Allemand D, Zoccola D(2011) A new coral carbonic anhydrase in Stylophora pistillata. Marine biotechnology (NY, USA), 13, 992 1002.

Brewer JW, Diehl JA (2000) PERK mediates cell-cycle exit during the mammalian unfolded protein response. Proceedings of the National Academy of Sciences of the United States of America, 97, 12625-12630.

Brown BE (1997) Coral bleaching : causes and consequences. Coral Reefs, 16, s129 s138.

Brown BE, Downs C, Dunne R, Gibb S (2002) Exploring the basis of thermotolerance in the reef coral Goniastrea aspera. Marine Ecology Progress Series, 242, 119-129.

Coles SL, Brown BE (2003) Coral bleaching - capacity for acclimatization and adaptation. Advances in Marine Biology, 46, 183-223.

Davy SK, Allemand D, Weis VM (2012) Cell biology of cnidarian-dinoflagellate symbiosis. Microbiology and molecular biology reviews : $M M B R, 76,229-261$.

DeSalvo MK, Voolstra CR, Sunagawa S et al. (2008) Differential gene expression during thermal stress and bleaching in the Caribbean coral Montastraea faveolata. Molecular ecology, 17, 3952-3971.

DeSalvo M, Sunagawa S, Voolstra C, Medina M (2010) Transcriptomic responses to heat stress and bleaching in the elkhorn coral Acropora palmata. Marine Ecology Progress Series, 402, 97-113.
Desalvo MK, A E SS, Medina M(2012) Transcriptomic responses to darkness stress point to common coral bleaching mechanisms. Coral Reefs, 31, 215-228.

Downs CA, Mueller E, Phillips S, Fauth JE, Woodley CM (2000) A molecular biomarker system for assessing the health of coral (Montastraea faveolata) during heat stress. Marine biotechnology, (NY, USA)2, 533-544.

Downs CA, Fauth JE, Halas JC, Dustan P, Bemiss J, Woodley CM (2002) Oxidative stress and seasonal coral bleaching. Free radical biology \& medicine, 33, 533-543.

Downs CA, Ostrander GK, Rougee L et al. (2012) The use of cellular diagnostics for identifying sub-lethal stress in reef corals. Ecotoxicology, London England, 21, 768 782.

Drake JL, Mass T, Haramaty L, Zelzion E, Bhattacharya D, Falkowski PG (2013) Proteomic analysis of skeletal organic matrix from the stony coral Stylophora pistillata. Proceedings of the National Academy of Sciences of the United States of America, 110, 3788-3793.

Edge SE, Morgan MB, Gleason DF, Snell TW (2005) Development of a coral cDNA array to examine gene expression profiles in Montastraea faveolata exposed to environmental stress. Marine pollution bulletin, 51, 507-523.

Esper EJC (1797) Fortsetzungen der Pflanzenthiere in Abbildungen nach der Natur mit Farben erleuchtet nebst Beschreibungen. Erster Theil. (Nürnberg). 230 pp.

Fitt W, Brown B, Warner M, Dunne R (2001) Coral bleaching: interpretation of thermal tolerance limits and thermal thresholds in tropical corals. Coral Reefs, 20, 5165.

Gattuso J-P, Allemand D, Frankignoulle M (1999) Photosynthesis and calcification at cellular, organismal and community levels in coral reefs : a review on interactions and control by carbonate. American zoologist, 183, 160-183.

Haas IG (1994) BiP (GRP78), an essential hsp70 resident protein in the endoplasmic reticulum Dedicated. Experientia, 50, 1012-1020.

Hahn J, Hu Z, Thiele DJ, Iyer VR (2004) Genome-wide analysis of the biology of stress responses through heat shock transcription factor. Molecular and cellular biology, 24, 5249-5256.

Hetz C (2012) The unfolded protein response: controlling cell fate decisions under ER stress and beyond. Nature reviews. Molecular cell biology, 13, 89-102.

Hoegh-Guldberg O (2010) Coral reef ecosystems and anthropogenic climate change. Regional Environmental Change, 11, 215-227.

Intergovernmental Panel on Climate Change (IPCC) (2007) Climate change 2007: The physical science basis. Summary for policy- makers. Contribution of working group I to the fourth assessment report of the Intergovernmental Panel on Climate Change. chapter 3: Climate change and its impacts in the near and long term under different scenarios, pp. 44-54.

Kaniewska P, Campbell PR, Kline DI, Rodriguez-Lanetty M, Miller DJ, Dove S, Hoegh-Guldberg O (2012) Major cellular and physiological impacts of ocean acidification on a reef building coral. PLOS ONE, 7, e34659.

Karako-Lampert S, Zoccola D, Salmon-Divon M et al. (2014) Transcriptome analysis of the scleractinian coral Stylophora pistillata. PLoS One, 9, e88615.

Kenkel CD, Meyer E, Matz MV (2013) Gene expression under chronic heat stress in populations of the mustard hill coral (Porites astreoides) from different thermal environments. Molecular ecology, 22, 4322-4334.

Kriegenburg F, Ellgaard L, Hartmann-Petersen R (2012) Molecular chaperones in targeting misfolded proteins for ubiquitin-dependent degradation. The Federation of European Biochemical Societies journal, 279, 532-542.

Kültz D (2003) Evolution of the cellular stress proteome: from monophyletic origin to ubiquitous function. Journal of Experimental Biology, 206, 3119-3124.

Kültz D (2005) Molecular and evolutionary basis of the cellular stress response. Annual review of physiology, 67, 225-257.

Lengfeld T, Watanabe H, Simakov O et al. (2009) Multiple Wnts are involved in Hydra organizer formation and regeneration. Developmental biology, 330, 186-199.

Levitus S, Antonov JI, Boyer TP, Locarnini RA, Garcia HE, Mishonov AV. (2009) Global ocean heat content 1955-2008 in light of recently revealed instrumentation problems. Geophysical Research Letters, 36, L07608.

Levy O, Appelbaum L, Leggat W, Gothlif Y, Hayward DC, Miller DJ, Hoegh-Guldberg O (2007) Light-responsive cryptochromes from a simple multicellular animal, the coral Acropora millepora. Science, 318, 467-470.

Levy O, Kaniewska P, Alon S et al. (2011) Complex diel cycles of gene expression in coral-algal symbiosis. Science, (NY, USA), 331, 175.

Loya Y (1976) The red sea coral stylophora pistillata is an $r$ strategist. Nature, 259, $478-480$.

Mayfield AB, Gates RD (2007) Osmoregulation in anthozoan-dinoflagellate symbiosis. Comparative biochemistry and physiology Part A Molecular integrative physiology, 147, $1-10$.

Moberg F, Folke C (1999) Ecological goods and services of coral reef ecosystems. Ecological economics, 29, 215-233. 
Obura DO (2009) Reef corals bleach to resist stress. Marine Pollution Bulletin, 58, 206 212.

Polato NR, Voolstra CR, Schnetzer J et al. (2010) Location-specific responses to thermal stress in larvae of the reef-building coral Montastraea faveolata. PLoS ONE, 5, e11221.

Portune KJ, Voolstra CR, Medina M, Szmant AM (2010) Development and heat stress-induced transcriptomic changes during embryogenesis of the scleractinian coral Acropora palmata. Marine genomics, 3, 51-62.

Rajagopalan S, Xu Y, Brenner MB (1994) Retention of unassembled components of integral membrane proteins by calnexin. Science, 263, 387-390.

Reaser JK, Pomerance R, Thomas PO (2000) Coral bleaching and global climate change: scientific findings and policy recommendations. Conservation Biology, 14, 1500-1511

Richier S, Rodriguez-Lanetty M, Schnitzler CE, Weis VM (2008) Response of the symbiotic cnidarian Anthopleura elegantissima transcriptome to temperature and UV increase.. Comparative biochemistry and physiology Part D, Genomics \& proteomics, 3, 283-289.

Rinkevich B, Loya Y (1985) Intraspecific competition in a reef coral: effects on growth and reproduction. Oecologia, 66, 100-105.

Rodda SJ, McMahon AP (2006) Distinct roles for Hedgehog and canonical Wnt signaling in specification, differentiation and maintenance of osteoblast progenitors. Development, Cambridge England, 133, 3231-3244.

Rodriguez-Lanetty M, Harii S, Hoegh-Guldberg O (2009) Early molecular responses of coral larvae to hyperthermal stress. Molecular ecology, 18, 5101-5114.

Shaish L, Abelson A, Rinkevich B (2007) How plastic can phenotypic plasticity be? The branching coral Stylophora pistillata as a model system. PLoS ONE, 2, e644.

Smith MH, Ploegh HL, Weissman JS (2011) Road to ruin: targeting proteins for degradation in the endoplasmic reticulum. Science, (NY, USA), 334, 1086-1090.

Smoot ME, Ono K, Ruscheinski J, Wang P-L, Ideker T(2011) Cytoscape 2.8: new features for data integration and network visualization. Bioinformatics (Oxford, England), 27, 431-432.

Springer S, Spang A, Schekman R (1999) A primer on vesicle budding. Cell, 97, 145 148

Steen RG, Muscatine L (1987) Low temperature evokes rapid exocytosis of symbiotic algae by a sea anemone. Biological Bulletin, 172, 246-263.

Szklarczyk D, Franceschini A, Kuhn M et al. (2011) The STRING database in 2011: functional interaction networks of proteins, globally integrated and scored. Nucleic acids research, 39, D561-D568.

Szmant AM, Gassman NJ (1990) The effects of prolonged 'bleaching' on the tissue biomass and reproduction of the reef coral Montastrea annularis. Coral Reefs, 8, 217-224.

Tambutté É, Allemand D, I B, Gattuso J-P, Jaubert J (1995) An improved 45 Ca protocol for investigating physiological mechanisms in coral calcification. Marine biology, 122, 453-459.

Tambutté S, Tambutté E, Zoccola D et al. (2006) Characterization and role of carbonic anhydrase in the calcification process of the azooxanthellate coral Tubastrea aurea. Marine Biology, 151, 71-83.

Tyedmers J, Lerner M, Wiedmann M, Volkmer J, Zimmermann R (2003) Polypeptidebinding proteins mediate completion of co-translational protein translocation into the mammalian endoplasmic reticulum. EMBO Reports, 4, 505-510.

Vidal-Dupiol J, Adjeroud M, Roger E et al. (2009) Coral bleaching under thermal stress: putative involvement of host/symbiont recognition mechanisms. BMC physiology, 9, 14.

Voolstra CR, Schnetzer J, Peshkin L, Randall CJ, Szmant AM, Medina M (2009) Effects of temperature on gene expression in embryos of the coral Montastraea faveolata. BMC genomics, 10, 627.

Walter P, Ron D (2011) The unfolded protein response: from stress pathway to homeostatic regulation. Science, (NY, USA), 334, 1081-1086.

Weis VM (2008) Cellular mechanisms of cnidarian bleaching: stress causes the collapse of symbiosis. The Journal of experimental biology, 211, 3059-3066.

Weis VM, Davy SK, Hoegh-Guldberg O, Rodriguez-Lanetty M, Pringle JR (2008) Cell biology in model systems as the key to understanding corals. Trends in ecology $\mathcal{E}$ evolution, 23, 369-376.

Wood-Charlson EM, Hollingsworth LL, Krupp DA, Weis VM (2006) Lectin/glycan interactions play a role in recognition in a coral/dinoflagellate symbiosis. Cellular microbiology, 8, 1985-1993.

Yamashiro H (1995) The effects of HEBP, an inhibitor of mineral deposition, upon photosynthesis and calcification in the scleractinian. Journal of Experimental Marine Biology and Ecology, 191, 57-63.
Yum S (2006) Ubiquitin expression in soft coral (Scleronephthya gracillimum) exposed to environmental stresses. Korean Journal of Genetics, 28, 149-156.

Zapun A, Darby NJ, Tessier DC, Michalak M, Bergeron JJ, Thomas DY (1998) Enhanced catalysis of ribonuclease B folding by the interaction of calnexin or calreticulin with ERp57. The Journal of Biological Chemistry, 273, 6009-6012.

Zhu Y, Carroll M, Papa FR, Hochstrasser M, D'Andrea AD (1996) DUB-1, a deubiquitinating enzyme with growth-suppressing activity. Proceedings of the National Academy of Sciences of the United States of America, 93, 3275-3279.

Zoltewicz JS, Ashique AM, Choe Y et al. (2009) Wnt signaling is regulated by endoplasmic reticulum retention. PLOS ONE, 4, e6191.

\section{Supporting Information}

Additional Supporting Information may be found in the online version of this article:

Data S1. Materials and methods.

Figure S1. Graphical illustration of the experimental design. Figure S2. Principle component analysis (PCA). All the samples and replicates are plotted in a three-dimensional space using three principal components (PC) capturing $65.3 \%$ of total variability. This image was constructed using Partek Genomics Suite $^{\mathrm{TM}}$ software.

Figure S3. Venn diagram of all differentially expressed genes. The Venn diagram presents differentially expressed genes in the 28 ( $\mathrm{t} 1$ vs. $\mathrm{c} 1$ ), 32 ( $\mathrm{t} 2 \mathrm{vs} . \mathrm{c} 2$ ) and $34^{\circ} \mathrm{C}$ ( $\mathrm{t} 3$ vs. $\mathrm{c} 3$ ) trials. The number of genes is indicated within each field.

Figure S4. The relative expression of selected genes assessed via quantitative real-time PCR (ddCt). The expression levels of (A) dnajc3 (DnaJ homolog subfamily C member 3), (B) pdia6 (protein disulfide-isomerase A6) (C) Collagen alpha and (D) Carbonic anhydrase 6, in treatments $1\left(28^{\circ} \mathrm{C}\right)$ and 3 $\left(34{ }^{\circ} \mathrm{C}\right)$ (indicted in black) and their corresponding controls (indicted in gray) are shown. Each $\mathrm{dCt}$ was normalized to a housekeeping gene: 60S Ribosomal protein L22. Error bars indicate the standard error.

Figure S5. Fold change values of selected up-regulated (A) and down-regulated (B) genes. The fold changes of genes for ER stress and protein folding in the ER and proteasomal ubiquitin-mediated proteolysis (A), and genes for extracellular matrix organization, Wnt signaling, Notch signaling and actin cytoskeleton organization (B) are shown with respect to temperature treatments 1,2 and 3. The color-scale legend indicating the relative fold change is shown on the right. This figure was constructed using EXPANDER software.

Figure S6. Venn diagram of total differentially expressed genes in preliminary $32{ }^{\circ} \mathrm{C}$ and current 32 and $34{ }^{\circ} \mathrm{C}$ trials. The number of genes is indicated within each field.

Table S1. A list of 163 differentially expressed genes 'Common genes' - either up- or down-regulated, at all three sampled temperatures. -1 and 1 indicate significant (FDR $P<0.05)$ down- and up-regulation, respectively.

Table S2. Down-regulated genes from the skeletal organic matrix (SOM) predicted proteins identified by Drake et al. 2013 proteomic analysis, in the $28^{\circ} \mathrm{C}$ (t1 vs. c1), $32^{\circ} \mathrm{C}$ ( $\mathrm{t} 2 \mathrm{vs}$. c2) and $34^{\circ} \mathrm{C}$ (t3 vs. c3) trials. $\downarrow$ and $\uparrow$ indicate significant (FDR $\mathrm{p}<0.05)$ down-regulated and up-regulated genes, respectively. 